Article

\title{
Characterization of Fumonisin A-Series by High-Resolution Liquid Chromatography-Orbitrap Mass Spectrometry
}

\author{
Masayoshi Tamura ${ }^{1,2}$, Naoki Mochizuki ${ }^{1, *}$, Yasushi Nagatomi ${ }^{1}$, Akira Toriba ${ }^{3}$ and \\ Kazuichi Hayakawa ${ }^{3}$
}

1 Research Laboratories for Food Safety Chemistry, Asahi Group Holdings, Ltd., 1-21, Midori 1-chome, Moriya-shi, Ibaraki 302-0106, Japan; E-Mails: masayoshi.tamura@asahigroup-holdings.com (M.T.); yasushi.nagatomi@asahigroup-holdings.com (Y.N.)

2 Graduate School of Medical Sciences, Kanazawa University, Kakuma-machi, Kanazawa-shi, Kanazawa 920-1192, Japan

3 Institute of Medical, Pharmaceutical and Health Sciences, Kanazawa University, Kakuma-machi, Kanazawa-shi, Kanazawa 920-1192, Japan; E-Mails: toriba@p.kanazawa-u.ac.jp (A.T.); hayakawa@p.kanazawa-u.ac.jp (K.H.)

* Author to whom correspondence should be addressed;

E-Mail: naoki.mochizuki@asahigroup-holdings.com;

Tel.: +81-297-46-1827; Fax: +81-297-46-1506.

Received: 4 July 2014; in revised form: 8 August 2014 / Accepted: 12 August 2014 /

Published: 21 August 2014

Abstract: Fumonisin A-series (FAs) in a reference material of corn sample that was
naturally contaminated with fumonisins was characterized using high-resolution liquid
chromatography-Orbitrap mass spectrometry (LC-Orbitap MS). Peaks for fumonisin B1
(FB1), fumonisin B2 (FB2), and fumonisin B3 (FB3), in addition to three peaks corresponding
to unknown compounds I, II, and III, were detected in the chromatogram for the corn
sample. Fragment ion analysis for FB1, FB2, and FB3 showed that while the ions formed
at $m / z$ values of $200-800$ were similar to those formed by the cleavage of the tricarballylic
acids and the hydroxyl groups, the fragmentation patterns at $m / z$ values of $50-200$ varied
depending on the hydroxyl group locations in the compounds. Fragment ion analysis of
compounds I-III revealed structural similarities to FBs, only differing by an additional
$\mathrm{C}_{2} \mathrm{H}_{2} \mathrm{O}$ in the unknown compounds. Using these results and by comparing the product ion
mass spectra of compound I with fumonisin A1 (FA1) synthesized from FB1 standards,
compounds I-III were hypothesized to be $N$-acetyl analogs of FBs: fumonisins A1 (FA1),
A2 (FA2), and A3 (FA3). The method for determining concentrations was validated with 
FA1, FB1, FB2, and FB3 standards and applied to analyze the reference material. The FB1, FB2, and FB3 analytical levels were within acceptance limits and the amount of FA1 in the material was $\sim 15 \%$ of FB1 amount at $4.2 \mathrm{mg} / \mathrm{kg}$.

Keywords: LC-Orbitrap MS; fumonisin A; corn

\section{Introduction}

There is significant worldwide concern over the health risks posed by the presence of fumonisins (chemical structure shown in Figure 1), which are one of the key mycotoxin contaminants in corn. In particular, fumonisin B1 (FB1) causes equine leukoencephalomalacia, porcine pulmonary edema, and induces esophageal cancer in humans [1,2]. The fumonisin B-series (FBs) is known to inhibit sphingosine $\mathrm{N}$-acyltransferase (ceramide synthase) in sphingolipid metabolism, which is important for the maintenance of membranes in all eukaryotic cells [1-3]. Additionally, FB1 is classified as 2B (possibly carcinogenic to humans) by the International Agency for Research on Cancer (IARC) [3]. Since the natural occurrence of FBs including FB1 have been reported worldwide, maximum levels for FBs in corn and corn products have been established in several countries including the USA and the EU [4,5]. Additionally, the Codex Alimentarius Commission has also advanced debates on establishing regulatory limits. There is a great desire for further research in the area of FBs, since there is much unknown information regarding them, such as the causal relationship between the action mechanisms of fumonisin and the onset of disease.

Figure 1. Chemical structure of fumonisins.

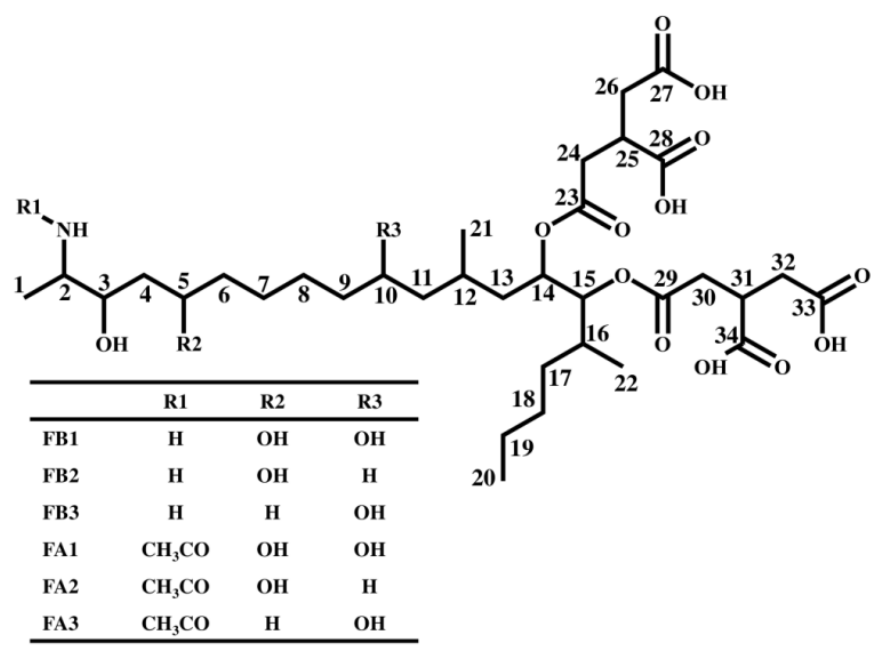

In addition to FBs, several analogs of this group including fumonisin A-series ( $N$-acetyl analogs, FAs), the fumonisin C-series (demethyl analogs, FCs), and the fumonisin P-series ( $N$-3-hydroxypiridinium analogs, FPs) have been discovered in the culture media of genus Fusarium. They are produced by Fusarium moniliforme, $F$. verticillioides, $F$. proliferatum, $F$. nygami, and F. oxysporum [6-11]. Similar to FBs, there are toxicity reports suggesting that FAs also have the ability to inhibit sphingosine $N$-acyltransferase [12]. In addition, FCs and FPs are known to be phytotoxic and cytotoxic [13]. 
Since there have been few reports of the detection of the fumonisin analogs in foods and feeds directly ingested by humans and animals, the extent to which they pose toxicity and contamination risks to cereals is unclear.

Recently, liquid chromatography (LC) coupled with triple-quadrupole mass spectrometry has been widely used for the quantification of mycotoxins including fumonisins in foods [14]. The triple-quadrupole mass spectrometry enables highly sensitive and selective detection of targeted compounds, although it is less suitable for a comprehensive determination since the analysis is performed by eliminating non-targeted compounds. In order to comprehensively analyze the mycotoxins, the LC-Orbitrap mass spectrometer (MS) has been introduced for the simultaneous screening $[15,16]$ and characterization of mycotoxins [17-19], which enables comprehensive analysis with high selectivity by providing high resolution and enables exact mass measurements for a full mass scan. Further, this technique allows the estimation of the formulae of fragment ions by incorporating a quadrupole mass filter and collision cell in the Orbitrap.

In the present study, we have attempted to detect fumonisins analogs in commercially available reference material of corn sample (MTC-9999E) that was naturally contaminated with fumonisins using Q-Exactive, which is Orbitrap MS equipped with a quadrupole mass filter and a collision cell. We have also attempted to deduce the structure of the compounds detected in the product ion mass spectra, by performing a fragment analysis. Additionally, a technique to determine the amount of FB1, FB2, FB3, and fumonisin A1 (FA1) has been developed and applied for the quantification of FA1 in MTC-9999E.

\section{Results and Discussion}

\subsection{Determination of Fumonisins by an LC-Orbitrap}

Figure 2 shows chromatograms of the prepared MTC-9999E obtained with a full mass scan. The retention time for the FB1, FB2, and FB3 peaks detected from the corn sample were quite similar to those obtained for standard solutions. The peaks for FB1, FB2, and FB3 and three unknown compounds (hereafter referred to as compounds I, II, and III) were simultaneously detected and the measured mass, the theoretical mass, the mass error, and the calculated formulae are shown in Table 1. As seen in the table, the only difference between the calculated formulae of compounds I, II, and III and FB1, FB2, and FB3 was that the former contained an additional $\mathrm{C}_{2} \mathrm{H}_{2} \mathrm{O}$ compared to the latter. This suggests that compounds I, II, and III are likely to be FA1, fumonisin A2 (FA2), and fumonisin A3 (FA3), which are $N$-acetyl analogs of FB1, FB2, and FB3, respectively. Therefore, the product ion spectra for each peak were measured, and the fragment ions were structurally characterized, as described next.

Table 1. Characteristic peak for FB1, FB2, FB3, and unknown compounds in MTC-9999E.

\begin{tabular}{ccccccc}
\hline Factor & FB1 & FB2 & FB3 & Compound I & Compound II & Compound III \\
\hline Measured mass $(m / z)$ & 722.3973 & 706.4020 & 706.4015 & 764.4059 & 748.4123 & 748.4118 \\
Calculated formula & $\mathrm{C}_{34} \mathrm{H}_{60} \mathrm{NO}_{15}{ }^{+}$ & $\mathrm{C}_{34} \mathrm{H}_{60} \mathrm{NO}_{14}{ }^{+}$ & $\mathrm{C}_{34} \mathrm{H}_{60} \mathrm{NO}_{14}^{+}$ & $\mathrm{C}_{36} \mathrm{H}_{62} \mathrm{NO}_{16}^{+}$ & $\mathrm{C}_{36} \mathrm{H}_{62} \mathrm{NO}_{15}{ }^{+}$ & $\mathrm{C}_{36} \mathrm{H}_{62} \mathrm{NO}_{15}{ }^{+}$ \\
Theoretical mass $(m / z)$ & 722.3958 & 706.4008 & 706.4008 & 764.4063 & 748.4114 & 748.4114 \\
Mass error $(\mathrm{ppm})$ & 1.59 & 1.21 & 0.66 & -0.48 & 1.20 & 0.54 \\
\hline
\end{tabular}


Figure 2. Chromatograms of the compounds in MTC-9999E and the standard solutions of FB1, FB2, and FB3: (A) FB1 in the sample; (B) FB2 and FB3 in the sample; (C) compound I; (D) compounds II and III; (E) FB1 standard; and (F) FB2 and FB3 standards.

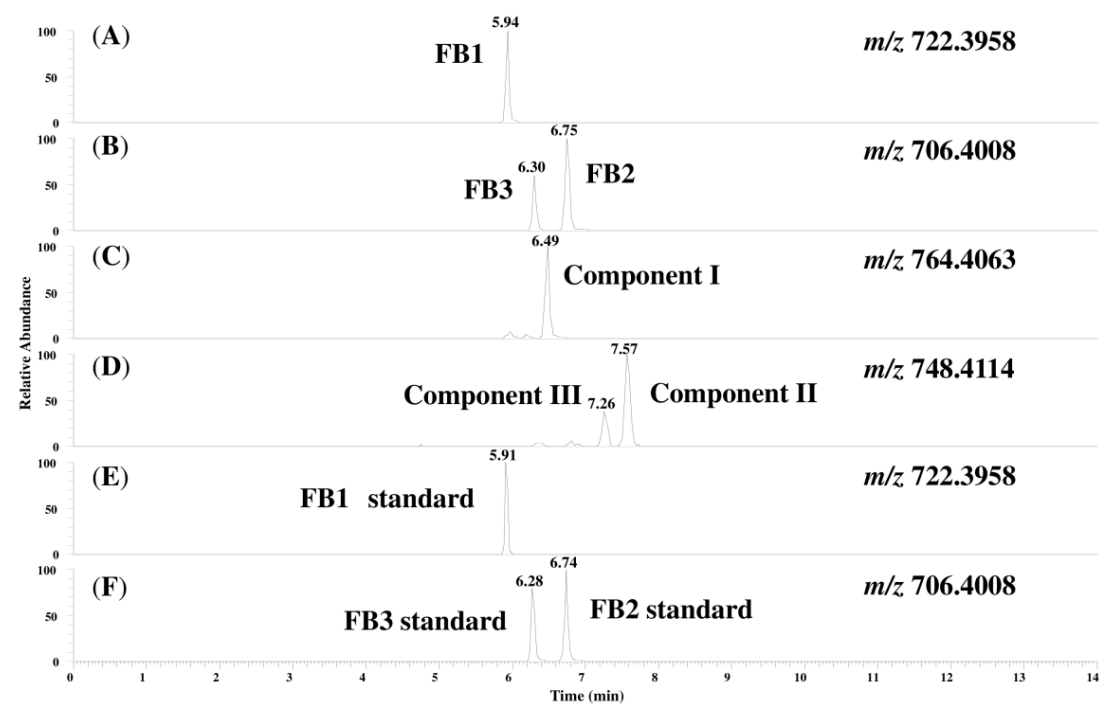

\subsection{Characterization of the Fragment Ions for FB1, FB2, and FB3}

Figure 3 shows product ion mass spectra of FB1, FB2, and FB3 standard solutions. The peaks in the spectra are labeled with identification (ID) numbers, corresponding to the numbers in Table 2, which summarizes the measured mass, the calculated formula, and the mass error for each spectrum. The product ion mass spectra of FB1, FB2, and FB3 in the corn sample were similar to those of the standard solutions.

Figure 3. Product ion mass spectra of standard solutions of FB1, FB2, and FB3 (A) FB1 standard; (B) FB2 standard; and (C) FB3 standard.

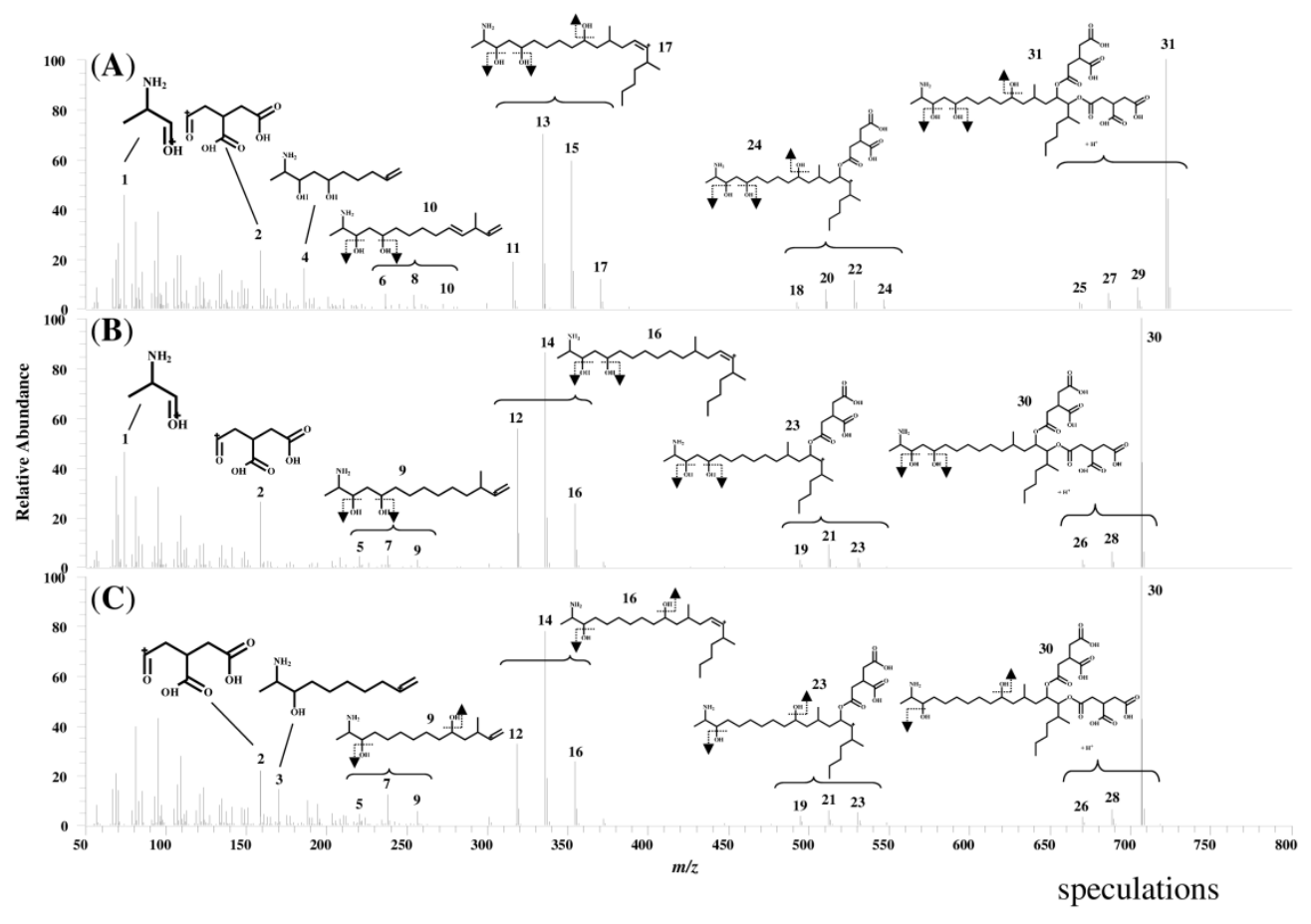


Table 2. Characteristic peak assignment of the product ion mass spectra of FB1, FB2, and FB3 standard solutions.

\begin{tabular}{|c|c|c|c|c|c|c|c|c|c|}
\hline \multirow[b]{2}{*}{ ID } & \multicolumn{3}{|c|}{ FB1 } & \multicolumn{3}{|c|}{ FB2 } & \multicolumn{3}{|c|}{ FB3 } \\
\hline & $\begin{array}{c}\text { Measured } \\
\text { Mass } \\
(m / z) \\
\end{array}$ & $\begin{array}{c}\text { Calculated } \\
\text { Formula } \\
{[\mathbf{M}+\mathbf{H}]^{+}} \\
\end{array}$ & $\begin{array}{l}\text { Mass } \\
\text { Error } \\
(\mathrm{ppm}) \\
\end{array}$ & $\begin{array}{c}\text { Measured } \\
\text { Mass } \\
(m / z) \\
\end{array}$ & $\begin{array}{c}\text { Calculated } \\
\text { Formula } \\
{[\mathbf{M}+\mathbf{H}]^{+}} \\
\end{array}$ & $\begin{array}{l}\text { Mass } \\
\text { Error } \\
(\mathrm{ppm}) \\
\end{array}$ & $\begin{array}{c}\text { Measured } \\
\text { Mass } \\
(m / z) \\
\end{array}$ & $\begin{array}{c}\text { Calculated } \\
\text { Formula } \\
{[\mathbf{M}+\mathbf{H}]^{+}} \\
\end{array}$ & $\begin{array}{l}\text { Mass } \\
\text { Error } \\
(\mathrm{ppm}) \\
\end{array}$ \\
\hline 1 & 74.0601 & $\mathrm{C}_{3} \mathrm{H}_{8} \mathrm{NO}$ & 1.17 & 74.0601 & $\mathrm{C}_{3} \mathrm{H}_{8} \mathrm{NO}$ & 1.17 & & & \\
\hline 2 & 159.0290 & $\mathrm{C}_{6} \mathrm{H}_{7} \mathrm{O}_{5}$ & 1.40 & 159.0290 & $\mathrm{C}_{6} \mathrm{H}_{7} \mathrm{O}_{5}$ & 0.92 & 159.0290 & $\mathrm{C}_{6} \mathrm{H}_{7} \mathrm{O}_{5}$ & 1.21 \\
\hline 3 & & & & & & & 170.1540 & $\mathrm{C}_{10} \mathrm{H}_{20} \mathrm{NO}$ & 0.39 \\
\hline 4 & 186.1492 & $\mathrm{C}_{10} \mathrm{H}_{20} \mathrm{NO}_{2}$ & 1.77 & & & & & & \\
\hline 5 & & & & 220.2059 & $\mathrm{C}_{15} \mathrm{H}_{26} \mathrm{~N}$ & -0.35 & 220.2058 & $\mathrm{C}_{15} \mathrm{H}_{26} \mathrm{~N}$ & -1.03 \\
\hline 6 & 236.2013 & $\mathrm{C}_{15} \mathrm{H}_{26} \mathrm{NO}$ & 1.77 & & & & & & \\
\hline 7 & & & & 238.2168 & $\mathrm{C}_{15} \mathrm{H}_{28} \mathrm{NO}$ & 0.96 & 238.2167 & $\mathrm{C}_{15} \mathrm{H}_{28} \mathrm{NO}$ & 0.56 \\
\hline 8 & 254.2118 & $\mathrm{C}_{15} \mathrm{H}_{28} \mathrm{NO}_{2}$ & 1.44 & & & & & & \\
\hline 9 & & & & 256.2276 & $\mathrm{C}_{15} \mathrm{H}_{30} \mathrm{NO}_{2}$ & 1.93 & 256.2272 & $\mathrm{C}_{15} \mathrm{H}_{30} \mathrm{NO}_{2}$ & 0.26 \\
\hline 10 & 272.2226 & $\mathrm{C}_{15} \mathrm{H}_{30} \mathrm{NO}_{3}$ & 0.88 & & & & & & \\
\hline 11 & 316.3001 & $\mathrm{C}_{22} \mathrm{H}_{38} \mathrm{~N}$ & 0.83 & & & & & & \\
\hline 12 & & & & 318.3157 & $\mathrm{C}_{22} \mathrm{H}_{40} \mathrm{~N}$ & 0.65 & 318.3158 & $\mathrm{C}_{22} \mathrm{H}_{40} \mathrm{~N}$ & 0.85 \\
\hline 13 & 334.3106 & $\mathrm{C}_{22} \mathrm{H}_{40} \mathrm{NO}$ & 0.59 & & & & & & \\
\hline 14 & & & & 336.3263 & $\mathrm{C}_{22} \mathrm{H}_{42} \mathrm{NO}$ & 0.51 & 336.3262 & $\mathrm{C}_{22} \mathrm{H}_{42} \mathrm{NO}$ & 0.42 \\
\hline 15 & 352.3213 & $\mathrm{C}_{22} \mathrm{H}_{42} \mathrm{NO}_{2}$ & 0.72 & & & & & & \\
\hline 16 & & & & 354.3369 & $\mathrm{C}_{22} \mathrm{H}_{44} \mathrm{NO}_{2}$ & 0.56 & 354.3369 & $\mathrm{C}_{22} \mathrm{H}_{44} \mathrm{NO}_{2}$ & 0.56 \\
\hline 17 & 370.3318 & $\mathrm{C}_{22} \mathrm{H}_{44} \mathrm{NO}_{3}$ & 0.58 & & & & & & \\
\hline 18 & 492.3330 & $\mathrm{C}_{28} \mathrm{H}_{46} \mathrm{NO}_{6}$ & 2.18 & & & & & & \\
\hline 19 & & & & 494.3478 & $\mathrm{C}_{28} \mathrm{H}_{48} \mathrm{NO}_{6}$ & 0.27 & 494.3480 & $\mathrm{C}_{28} \mathrm{H}_{48} \mathrm{NO}_{6}$ & 0.76 \\
\hline 20 & 510.3431 & $\mathrm{C}_{28} \mathrm{H}_{48} \mathrm{NO}_{7}$ & 1.14 & & & & & & \\
\hline 21 & & & & 512.3592 & $\mathrm{C}_{28} \mathrm{H}_{50} \mathrm{NO}_{7}$ & 1.98 & 512.3593 & $\mathrm{C}_{28} \mathrm{H}_{50} \mathrm{NO}_{7}$ & 2.10 \\
\hline 22 & 528.3538 & $\mathrm{C}_{28} \mathrm{H}_{50} \mathrm{NO}_{8}$ & 1.38 & & & & & & \\
\hline 23 & & & & 530.3693 & $\mathrm{C}_{28} \mathrm{H}_{52} \mathrm{NO}_{8}$ & 0.98 & 530.3691 & $\mathrm{C}_{28} \mathrm{H}_{52} \mathrm{NO}_{8}$ & 0.63 \\
\hline 24 & 546.3630 & $\mathrm{C}_{28} \mathrm{H}_{52} \mathrm{NO}_{9}$ & -1.13 & & & & & & \\
\hline 25 & 668.3648 & $\mathrm{C}_{34} \mathrm{H}_{54} \mathrm{NO}_{12}$ & 1.04 & & & & & & \\
\hline 26 & & & & 670.3806 & $\mathrm{C}_{34} \mathrm{H}_{56} \mathrm{NO}_{12}$ & 1.27 & 670.3789 & $\mathrm{C}_{34} \mathrm{H}_{56} \mathrm{NO}_{12}$ & -1.27 \\
\hline 27 & 686.3731 & $\mathrm{C}_{34} \mathrm{H}_{56} \mathrm{NO}_{13}$ & -2.29 & & & & & & \\
\hline 28 & & & & 688.3909 & $\mathrm{C}_{34} \mathrm{H}_{58} \mathrm{NO}_{13}$ & 0.87 & 688.3903 & $\mathrm{C}_{34} \mathrm{H}_{58} \mathrm{NO}_{13}$ & -0.01 \\
\hline 29 & 704.3867 & $\mathrm{C}_{34} \mathrm{H}_{58} \mathrm{NO}_{14}$ & 2.18 & & & & & & \\
\hline 30 & & & & 706.4016 & $\mathrm{C}_{34} \mathrm{H}_{60} \mathrm{NO}_{14}$ & 1.02 & 706.4016 & $\mathrm{C}_{34} \mathrm{H}_{60} \mathrm{NO}_{14}$ & 1.10 \\
\hline 31 & 722.3966 & $\mathrm{C}_{34} \mathrm{H}_{60} \mathrm{NO}_{15}$ & 1.11 & & & & & & \\
\hline
\end{tabular}

It is believed that fragment ions at $m / z$ values of $200-800$ were formed by the cleavage of the tricarballylic acids (TCAs) and the hydroxyl groups from the precursor ions, and these characteristic fragmentations were common to FB1, FB2, and FB3. On the other hand, at $m / z$ values of $50-200$, different fragment ions were thought to form depending on the positions of the hydroxyl groups in compound. In the case of fragment ions from FB1, ID 4 of the 10-carbon chain was formed by the $\mathrm{C}-\mathrm{C}$ cleavage at $\mathrm{C}$-10, and ID 1 of 2-amino-1-propanol (APA) was formed by the cleavage at C-5. In the case of FB2, the ID 1 of APA was formed by the cleavage at C-5 similar to the fragment ions of FB1, 
whereas an ion of a 10-carbon chain, like ID 3 and ID 4, was not able to form due to lack of a hydroxyl group at C-10. In contrast, in the case of FB3, ID 1 was not present, owing to lack of a hydroxyl group at C-5, whereas an ID 3 of the 10-carbon chain was formed by the cleavage at C-10. ID 2 was present in all of three product ion spectra, and the calculated formula is $\mathrm{C}_{6} \mathrm{H}_{7} \mathrm{O}_{5}$, possibly representing TCA.

These results indicate that the fragmentation of FB1, FB2, and FB3 exhibits characteristic patterns, such as the formation of fragment ions by the cleavage of TCAs and the hydroxyl groups from the precursor ion, the formation of different fragment ions depending on the position of the hydroxyl group, and the formation of TCA present in the each compound.

\subsection{Analysis of Fragment Ions for Compounds I, II, and III}

Figure 4 shows the product ion spectra of compounds I, II, and III and Table 3 summarizes the measured mass, the calculated formula, and the mass error for the fragment ions of these compounds.

Figure 4. Product ion mass spectra of compounds I, II, and III (A) compound I; (B) compound II; and (C) compound III.

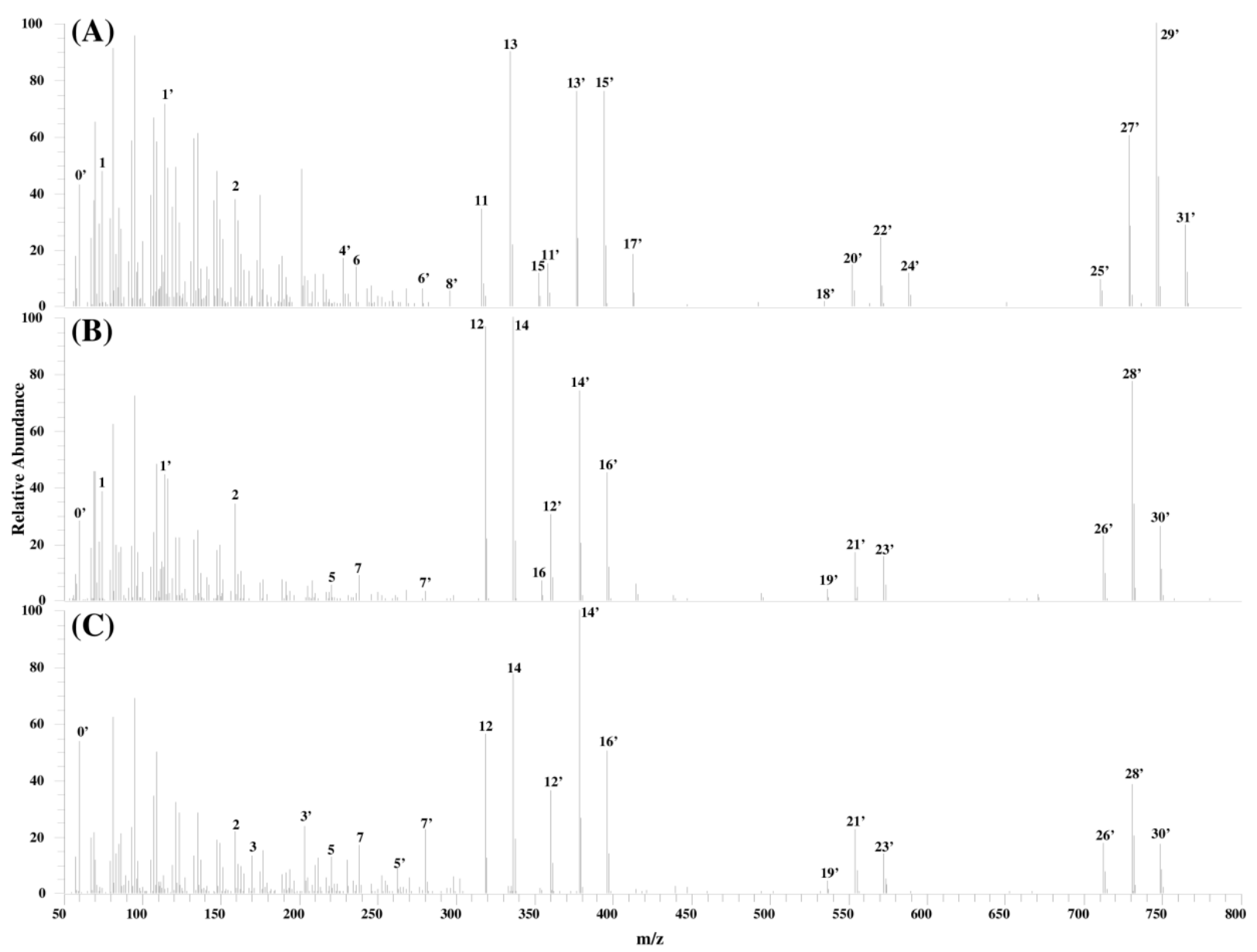

Compounds I, II, and III shows peaks with the same calculated formulae as that of product ions generated from FB1, FB2, and FB3 in addition to product ions which differed by $\mathrm{C}_{2} \mathrm{H}_{2} \mathrm{O}$ from the product ions of FB1, FB2, and FB3. Please note that the ions having the same calculated formulae have been denoted with the same ID numbers in Table 3 and the calculated formulae for the ID numbers marked with a dash in Table 3 have an additional $\mathrm{C}_{2} \mathrm{H}_{2} \mathrm{O}$. 
Table 3. Characteristic peak assignment in the product ion mass spectra of compounds I, II, and III.

\begin{tabular}{|c|c|c|c|c|c|c|c|c|c|}
\hline \multirow[b]{2}{*}{ ID } & \multicolumn{3}{|c|}{ Compound I } & \multicolumn{3}{|c|}{ Compound II } & \multicolumn{3}{|c|}{ Compound III } \\
\hline & $\begin{array}{c}\text { Measured } \\
\text { Mass } \\
(m / z) \\
\end{array}$ & $\begin{array}{c}\text { Calculated } \\
\text { Formula } \\
{[\mathbf{M}+\mathbf{H}]^{+}} \\
\end{array}$ & $\begin{array}{l}\text { Mass } \\
\text { Error } \\
(\mathrm{ppm}) \\
\end{array}$ & $\begin{array}{l}\text { Measured } \\
\text { Mass }(m / z)\end{array}$ & $\begin{array}{c}\text { Calculated } \\
\text { Formula } \\
{[\mathbf{M}+\mathbf{H}]^{+}} \\
\end{array}$ & $\begin{array}{l}\text { Mass } \\
\text { Error } \\
(\mathbf{p p m}) \\
\end{array}$ & $\begin{array}{l}\text { Measured } \\
\text { Mass }(m / z)\end{array}$ & $\begin{array}{c}\text { Calculated } \\
\text { Formula } \\
{[\mathbf{M}+\mathbf{H}]^{+}} \\
\end{array}$ & $\begin{array}{l}\text { Mass } \\
\text { Error } \\
(\mathrm{ppm}) \\
\end{array}$ \\
\hline $0^{\prime}$ & 60.0444 & $\mathrm{C}_{2} \mathrm{H}_{6} \mathrm{NO}$ & 0.21 & 60.0445 & $\mathrm{C}_{2} \mathrm{H}_{6} \mathrm{NO}$ & 1.42 & 60.0444 & $\mathrm{C}_{2} \mathrm{H}_{6} \mathrm{NO}$ & 0.72 \\
\hline 1 & 74.0601 & $\mathrm{C}_{3} \mathrm{H}_{8} \mathrm{NO}$ & 0.25 & 74.0601 & $\mathrm{C}_{3} \mathrm{H}_{8} \mathrm{NO}$ & 0.97 & & & \\
\hline 1 ' & 116.0706 & $\mathrm{C}_{5} \mathrm{H}_{10} \mathrm{NO}_{2}$ & -0.35 & 116.0707 & $\mathrm{C}_{5} \mathrm{H}_{10} \mathrm{NO}_{2}$ & 0.70 & & & \\
\hline 2 & 159.0288 & $\mathrm{C}_{6} \mathrm{H}_{7} \mathrm{O}_{5}$ & -0.04 & 159.0289 & $\mathrm{C}_{6} \mathrm{H}_{7} \mathrm{O}_{5}$ & 0.53 & 159.0289 & $\mathrm{C}_{6} \mathrm{H}_{7} \mathrm{O}_{5}$ & 0.44 \\
\hline 3 & & & & & & & 170.1541 & $\mathrm{C}_{10} \mathrm{H}_{20} \mathrm{NO}$ & 0.75 \\
\hline $3^{\prime}$ & & & & & & & 212.1646 & $\mathrm{C}_{12} \mathrm{H}_{22} \mathrm{NO}_{2}$ & 0.21 \\
\hline $4^{\prime}$ & 228.1594 & $\mathrm{C}_{12} \mathrm{H}_{22} \mathrm{NO}_{3}$ & -0.13 & & & & & & \\
\hline 5 & & & & 220.2060 & $\mathrm{C}_{15} \mathrm{H}_{26} \mathrm{~N}$ & 0.29 & 220.2061 & $\mathrm{C}_{15} \mathrm{H}_{26} \mathrm{~N}$ & 0.42 \\
\hline $5^{\prime}$ & & & & & & & 262.2168 & $\mathrm{C}_{17} \mathrm{H}_{28} \mathrm{NO}$ & 0.99 \\
\hline 6 & 236.2003 & $\mathrm{C}_{15} \mathrm{H}_{26} \mathrm{NO}$ & -2.38 & & & & & & \\
\hline $6^{\prime}$ & 278.2114 & $\mathrm{C}_{17} \mathrm{H}_{28} \mathrm{NO}_{2}$ & -0.20 & & & & & & \\
\hline 7 & & & & 238.2167 & $\mathrm{C}_{15} \mathrm{H}_{28} \mathrm{NO}$ & 0.84 & 238.2164 & $\mathrm{C}_{15} \mathrm{H}_{28} \mathrm{NO}$ & -0.78 \\
\hline $7^{\prime}$ & & & & 280.2264 & $\mathrm{C}_{17} \mathrm{H}_{30} \mathrm{NO}_{2}$ & -2.70 & 280.2274 & $\mathrm{C}_{17} \mathrm{H}_{30} \mathrm{NO}_{2}$ & 0.89 \\
\hline $8^{\prime}$ & 296.2205 & $\mathrm{C}_{17} \mathrm{H}_{30} \mathrm{NO}_{3}$ & -2.07 & & & & & & \\
\hline 11 & 316.2997 & $\mathrm{C}_{22} \mathrm{H}_{38} \mathrm{~N}$ & -0.61 & & & & & & \\
\hline $11^{\prime}$ & 358.3106 & $\mathrm{C}_{24} \mathrm{H}_{40} \mathrm{NO}$ & 0.39 & & & & & & \\
\hline 12 & & & & 318.3156 & $\mathrm{C}_{22} \mathrm{H}_{40} \mathrm{~N}$ & 0.08 & 318.3155 & $\mathrm{C}_{22} \mathrm{H}_{40} \mathrm{~N}$ & -0.02 \\
\hline $12^{\prime}$ & & & & 360.3261 & $\mathrm{C}_{24} \mathrm{H}_{42} \mathrm{NO}$ & -0.12 & 360.3260 & $\mathrm{C}_{24} \mathrm{H}_{42} \mathrm{NO}$ & -0.37 \\
\hline 13 & 334.3102 & $\mathrm{C}_{22} \mathrm{H}_{40} \mathrm{NO}$ & -0.78 & & & & & & \\
\hline $13^{\prime}$ & 376.3208 & $\mathrm{C}_{24} \mathrm{H}_{42} \mathrm{NO}_{2}$ & -0.46 & & & & & & \\
\hline 14 & & & & 336.3261 & $\mathrm{C}_{22} \mathrm{H}_{42} \mathrm{NO}$ & 0.15 & 336.3260 & $\mathrm{C}_{22} \mathrm{H}_{42} \mathrm{NO}$ & -0.21 \\
\hline $14^{\prime}$ & & & & 378.3367 & $\mathrm{C}_{24} \mathrm{H}_{44} \mathrm{NO}_{2}$ & 0.12 & 378.3367 & $\mathrm{C}_{24} \mathrm{H}_{44} \mathrm{NO}_{2}$ & 0.12 \\
\hline 15 & 352.3202 & $\mathrm{C}_{22} \mathrm{H}_{42} \mathrm{NO}_{2}$ & -2.40 & & & & & & \\
\hline $15^{\prime}$ & 394.3315 & $\mathrm{C}_{24} \mathrm{H}_{44} \mathrm{NO}_{3}$ & -0.07 & & & & & & \\
\hline 16 & & & & 354.3371 & $\mathrm{C}_{22} \mathrm{H}_{4} \mathrm{NO}_{2}$ & 1.34 & & & \\
\hline $16^{\prime}$ & & & & 396.3475 & $\mathrm{C}_{24} \mathrm{H}_{46} \mathrm{NO}_{3}$ & 0.64 & 396.3473 & $\mathrm{C}_{24} \mathrm{H}_{46} \mathrm{NO}_{3}$ & 0.25 \\
\hline $17^{\prime}$ & 412.3418 & $\mathrm{C}_{24} \mathrm{H}_{46} \mathrm{NO}_{4}$ & -0.75 & & & & & & \\
\hline $18^{\prime}$ & 534.3431 & $\mathrm{C}_{30} \mathrm{H}_{48} \mathrm{NO}_{7}$ & 1.14 & & & & & & \\
\hline $19^{\prime}$ & & & & 536.3582 & $\mathrm{C}_{30} \mathrm{H}_{50} \mathrm{NO}_{7}$ & 0.08 & 536.3591 & $\mathrm{C}_{30} \mathrm{H}_{50} \mathrm{NO}_{7}$ & 1.66 \\
\hline $20^{\prime}$ & 552.3516 & $\mathrm{C}_{30} \mathrm{H}_{50} \mathrm{NO}_{8}$ & -2.67 & & & & & & \\
\hline $21^{\prime}$ & & & & 554.3691 & $\mathrm{C}_{30} \mathrm{H}_{52} \mathrm{NO}_{8}$ & 0.72 & 554.3691 & $\mathrm{C}_{30} \mathrm{H}_{52} \mathrm{NO}_{8}$ & 0.61 \\
\hline $22^{\prime}$ & 570.3637 & $\mathrm{C}_{30} \mathrm{H}_{52} \mathrm{NO}_{9}$ & -0.02 & & & & & & \\
\hline $23^{\prime}$ & & & & 572.3793 & $\mathrm{C}_{30} \mathrm{H}_{54} \mathrm{NO}_{9}$ & -0.06 & 572.3794 & $\mathrm{C}_{30} \mathrm{H}_{54} \mathrm{NO}_{9}$ & 0.15 \\
\hline $24^{\prime}$ & 588.3752 & $\mathrm{C}_{30} \mathrm{H}_{54} \mathrm{NO}_{10}$ & 1.63 & & & & & & \\
\hline $25^{\prime}$ & 710.3760 & $\mathrm{C}_{36} \mathrm{H}_{56} \mathrm{NO}_{13}$ & 2.00 & & & & & & \\
\hline $26^{\prime}$ & & & & 712.3914 & $\mathrm{C}_{36} \mathrm{H}_{58} \mathrm{NO}_{13}$ & 1.53 & 712.3902 & $\mathrm{C}_{36} \mathrm{H}_{58} \mathrm{NO}_{13}$ & -0.10 \\
\hline $27^{\prime}$ & 728.3850 & $\mathrm{C}_{36} \mathrm{H}_{58} \mathrm{NO}_{14}$ & -0.32 & & & & & & \\
\hline $28^{\prime}$ & & & & 730.4010 & $\mathrm{C}_{36} \mathrm{H}_{60} \mathrm{NO}_{14}$ & 0.23 & 730.4014 & $\mathrm{C}_{36} \mathrm{H}_{60} \mathrm{NO}_{14}$ & 0.82 \\
\hline $29^{\prime}$ & 746.3956 & $\mathrm{C}_{36} \mathrm{H}_{60} \mathrm{NO}_{15}$ & -0.24 & & & & & & \\
\hline $30^{\prime}$ & & & & 748.4123 & $\mathrm{C}_{36} \mathrm{H}_{62} \mathrm{NO}_{15}$ & 1.20 & 748.4118 & $\mathrm{C}_{36} \mathrm{H}_{62} \mathrm{NO}_{15}$ & 0.54 \\
\hline $31^{\prime}$ & 764.4059 & $\mathrm{C}_{36} \mathrm{H}_{62} \mathrm{NO}_{16}$ & -0.48 & & & & & & \\
\hline
\end{tabular}


For $m / z$ values of 700-800, IDs 25'-31' were observed at equal intervals. Since the difference between the calculated formulae suggested the presence of the hydroxyl groups, it was concluded that compound I had three hydroxyl groups, and that compounds II and III had two hydroxyl groups each. The same results were obtained for $m / z$ values of 500-600 (ID 18'-24').

At $m / z$ values of $300-450$, the same peaks (IDs $11-16$ ) of product ions generated from FB1, FB2, and FB3 were observed in addition to the peaks corresponding to FB1, FB2, and FB3 with an additional $\mathrm{C}_{2} \mathrm{H}_{2} \mathrm{O}$ (ID 11'-17'). It was assumed that the cleavage of $\mathrm{C}_{2} \mathrm{H}_{2} \mathrm{O}$ in compounds I, II, and III produced the same fragment ions as FB1, FB2, and FB3. This assumption was also made at $\mathrm{m} / z$ values of 50-300 where IDs 1-7, as well as IDs 1'-7', generated by the cleavage of $\mathrm{C}_{2} \mathrm{H}_{2} \mathrm{O}$ were observed. In addition, ID 2, which was a product ion common to FB1, FB2, and FB3, was also observed in the case of compounds I, II, and III. Considering that ID 2 represented TCA in the product ion mass spectra of FB1, FB2, and FB3, it was presumed that TCA is also bound to compounds I, II, and III. Further, different fragment ions depending on the positions of the hydroxyl groups were observed in the spectra of compounds I, II, and III. This is characteristic of the fragmentation in FBs. Spectra for compound I showed the existence of ID 4' and ID 1' formed presumably by the cleavage at C-10 and C-5, respectively. Compound II showed the presence of ID 1' and the absence of spectra like ID 3' and 4', whereas compound III showed the existence of ID $3^{\prime}$ and the absence of ID 1'. From these observations, it was assumed the hydroxyl groups are bound to compound I at C-5 and C-10, to compound II at C-10, and to compound III at C-5 positions.

It was hypothesized that compounds I, II, and III have TCAs, hydroxyl groups, and $\mathrm{C}_{2} \mathrm{H}_{2} \mathrm{O}$ and that the fragmentation of compounds I, II, and III are similar those of FB1, FB2, and FB3, respectively. Since compounds I, II, and III supposedly have similar structures to FBs, with an additional $\mathrm{C}_{2} \mathrm{H}_{2} \mathrm{O}$ in their structures, it was suggested that these compounds are FA1, FA2, and FA3, which are $N$-acetyl analogs of FB1, FB2, and FB3, respectively. In order to confirm the above hypothesis, we attempted to synthesize FA1 from the FB1 standard material, which is easily obtained, and compared the product ions of compound I with those of the synthesized FA1.

\subsection{Characterization of Compound I Using the FA1 Standard}

FA1, synthesized from the FB1 standard material, was analyzed using the LC-Orbitrap MS. The measured mass, the calculated formulae, the theoretical mass, and the mass error were 764.4087, $\mathrm{C}_{36} \mathrm{H}_{62} \mathrm{NO}_{16}{ }^{+}, 764.4063$, and 3.11 ppm, respectively.

The NMR spectral measurements of the synthesized product indicated a chemical shift of the proton at C-2 at $\sim 3.9 \mathrm{ppm}$. Since the chemical shift of the proton at C-2 was found to be $\sim 3.1 \mathrm{ppm}$ in the case of FB1, this result further validated that the synthesized compound is an $N$-acetyl analog of FB1.The chemical shifts $(\delta)$ for the other protons in the ${ }^{1} \mathrm{H}$ NMR (methanol- $\mathrm{d}_{4}$ ) measurements were $1.002(\mathrm{t}, J=0.012 \mathrm{~Hz}, 3 \mathrm{H}), 1.025-1.100(\mathrm{~m}, 6 \mathrm{H}), 1.235(\mathrm{~d}, J=0.012 \mathrm{~Hz}, 3 \mathrm{H}), 1.323-1.632(\mathrm{~m}, 18 \mathrm{H})$, 1.690-1.852 (m, 2H), 1.917 (brs, 1H), 2.052 (s, 3H), 2.573-2.944 (m, 8H), 3.254-3.335 (m, 2H), 3.719 (brs, 1H), 3.852-3.909 (m, 2H), 3.957-4.020 (m, 1H), 5.069 (dd, $J=0.005,0.014 \mathrm{~Hz}, 1 \mathrm{H})$, and $5.259(\mathrm{td}, J=0.005,0.018 \mathrm{~Hz}, 1 \mathrm{H})$. These results agreed with the values we observed for FB1 and those seen in previous studies [7,20]. Based on the findings, the synthesized compound was identified as FA1. The purity of the synthesized FA1 was determined to be $87.0 \%$. 
Figure 5 compares the chromatograms and product ion mass spectra of compound $\mathrm{I}$ in the corn sample and the synthesized FA1 standard. The similarity in their retention times and the profile of the product ion mass spectra lent further evidence that compound I was FA1.

Figure 5. Chromatograms and product ion mass spectra of compound I and synthesized FA1: (A) chromatogram of compound I in the sample; (B) chromatogram of synthesized FA1; (C) product ion mass spectrum of compound I in the sample; and (D) product ion mass spectrum of synthesized FA1.

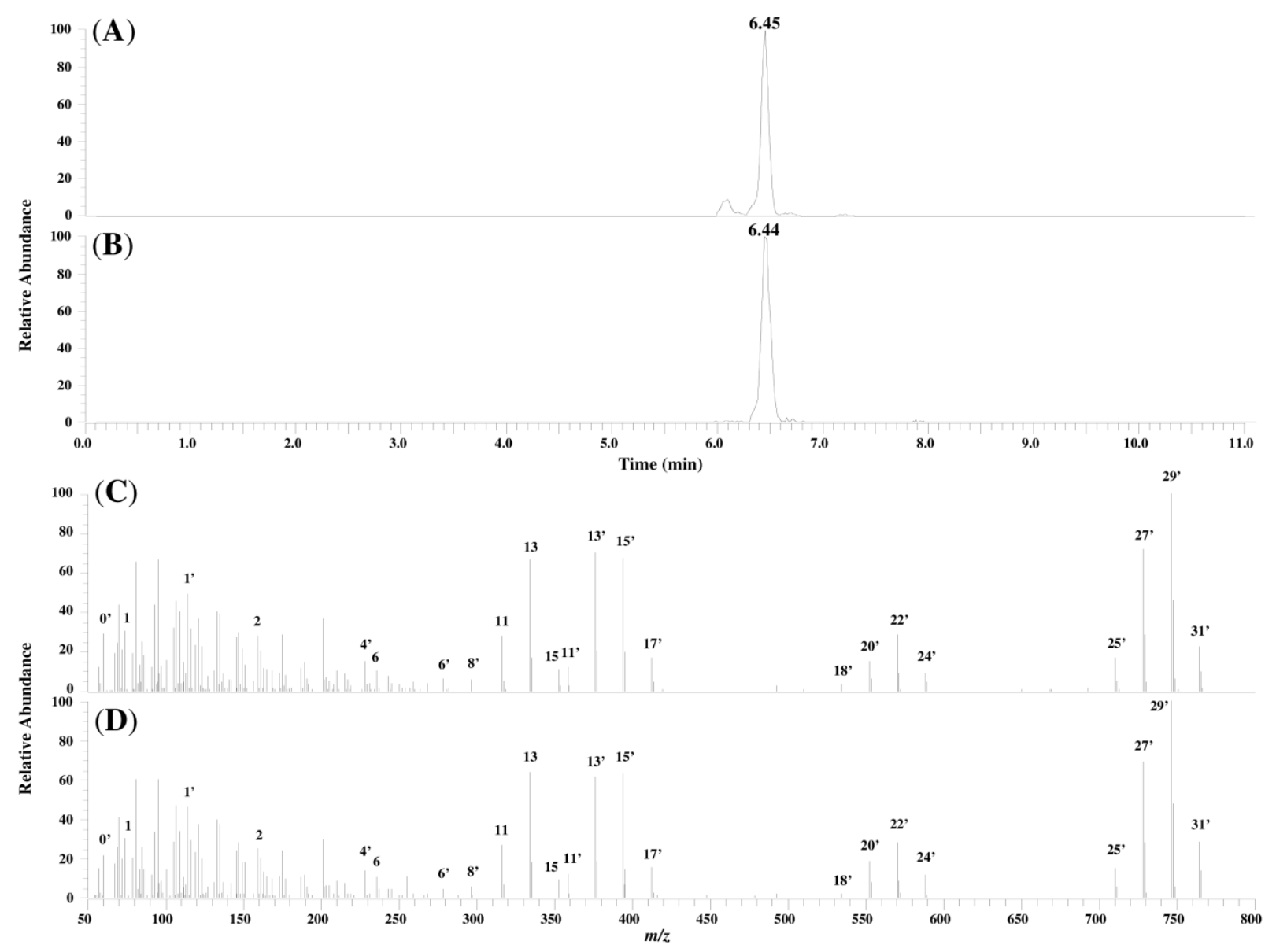

The main fragment ions generated from FA1 were identified from the product ion spectra. ID 0', ID 1', and ID 2 were assigned to $\mathrm{N}$-acetyl, 2-acetamide-1-propanol (the fragment ion formed by the cleavage of the hydroxyl group at C-5), and TCA, respectively. IDs 3'-4' and IDs 11'-13' were assigned to the fragment ions generated by the cleavage of the hydroxyl group at $\mathrm{C}-10$ and those generated by the cleavage of TCA and the hydroxyl groups, respectively. Considering the evidence in Section 2, along with the above results, it was probably indicated that compounds II and III are FA2 and FA3, respectively.

\subsection{Determination of FA1, FB1, FB2, and FB3 in MTC-9999E}

Next, the accuracy of the method for the determination of FA1, FB1, FB2, and FB3 was evaluated, and the amounts of FA1, FB1, FB2, and FB3 in the MTC-9999E sample were quantified. The results are shown in Table 4. 
Table 4. The performance of the method and the amount of fumonisins in MTC-9999E.

\begin{tabular}{ccccc}
\hline Validation item & FA1 & FB1 & FB2 & FB3 \\
\hline Linearity $(r)$ & 0.9987 & 0.9989 & 0.9995 & 0.9972 \\
Recovery $(\%)$ & 101.8 & 99.0 & 100.2 & 96.4 \\
Intraday-precision $(\%)$ & 5.3 & 9.0 & 5.0 & 10.8 \\
LOD $(\mu \mathrm{g} / \mathrm{kg})$ & 0.73 & 0.07 & 0.15 & 0.12 \\
LOQ $(\mu \mathrm{g} / \mathrm{kg})$ & 2.44 & 0.20 & 0.49 & 0.40 \\
Analytical level $(\mathrm{mg} / \mathrm{kg})$ & 4.2 & 28.6 & 8.9 & 2.0 \\
Acceptance limit $(\mathrm{mg} / \mathrm{kg})$ & - & $28.3 \pm 7.6$ & $7.1 \pm 1.9$ & $1.7 \pm 0.5$ \\
\hline
\end{tabular}

The coefficient of linearity, the recovery, the intraday precision, and the LODs were determined to be $>0.99,96.4 \%-101.8 \%, 5.0 \%-10.8 \%$, and $0.07-0.73 \mu \mathrm{g} / \mathrm{kg}$, respectively. Thus, it can be concluded that we have developed a well performing method for the simultaneous analysis of FA1, FB1, FB2, and FB3. The method was applied to the analysis of MTC-9999E. Since the individual concentrations of FB1 and FB2 in MTC-9999E were already known and were over the range of each of the calibration curves, the sample was diluted 10 times prior to analysis. The analytical levels of FB1, FB2, and FB3 in MTC-9999E were within the acceptance limits, which reconfirmed the validity of the method. The amount of FA1 in MTC-9999E was found to be $4.2 \mathrm{mg} / \mathrm{kg}$, which was approximately $15 \%$ of the amount of FB1. These findings confirm the presence of FAs in addition to FBs in corn, as potential food contaminants.

\section{Experimental Section}

\subsection{Sample, Chemicals, and Reagents}

Mycotoxin reference material (MTC-9999E) obtained from Trilogy Analytical laboratory (Washington, DC, USA) was used as the corn sample naturally contaminated with fumonisins. The acceptance limits incorporating $26.8 \%$ of uncertainty are $28.3 \pm 7.6 \mathrm{mg} / \mathrm{kg}$ of FB1, $7.1 \pm 1.9 \mathrm{mg} / \mathrm{kg}$ of $\mathrm{FB} 2$, and $1.7 \pm 0.5 \mathrm{mg} / \mathrm{kg}$ of FB3, respectively.

FB1 standard was obtained from Cayman Chemical Co. (Ann Arbor, MI, USA). Standard solutions containing $50 \mu \mathrm{g} / \mathrm{mL}$ of FB1, FB2, and FB3 in acetonitrile/water $(1 / 1 v / v)$ were from Romer Labs (Bukit Merah, Singapore). Methanol (LC/MS grade), acetonitrile (analytical grade), acetic acid (guaranteed reagent grade), ammonium acetate (analytical grade), dipotassium hydrogen phosphate (guaranteed reagent grade), $N, N$-dimethylformamide (guaranteed reagent grade), and acetic anhydride (guaranteed reagent grade) were purchased from Kanto Chemical Co., Inc. (Tokyo, Japan). Methanol-d $\mathrm{d}_{4}$ (NMR grade) and Supelpak 2 were obtained from Merck KGaA (Darmstadt, Germany) and Sigma-Aldrich (Bellefonte, PA, USA), respectively. Water was purified using a Millipore (Molsheim, France) Milli-Q system. Q-sep Q 110 used as a QuEChERS extraction kit was obtained from RESTEK (Bellefonte, PA, USA). MultiSep 229 Ochra used as a multi-functional cartridge was obtained from Romer Labs (Bukit Merah, Singapore). A PTFE filter with a mesh size of $0.20 \mu \mathrm{m}$ was procured from Advantec Toyo Kaisha, Ltd. (Tokyo, Japan). 


\subsection{Sample Preparation}

Sample preparation was carried out as previously described [21]. Namely, a $2.5 \mathrm{~g}$ sample was placed in a $50 \mathrm{~mL}$ polypropylene centrifuge tube and $20 \mathrm{~mL}$ of a $2 \%$ acetic acid aqueous solution/acetonitrile $(1: 1 \mathrm{v} / \mathrm{v})$ was added to the sample. They were mixed at $250 \mathrm{rpm}$ using a shaker (SR-2 DS; Taitec Saitama, Japan) for $1 \mathrm{~h}$. The contents of the Q-sep Q110 were then added to the tube. The mixture was vortexed for $20 \mathrm{~s}$ and centrifuged at $3000 \mathrm{rpm}$ for $5 \mathrm{~min}$. The supernatant (acetonitrile phase) was frozen at $-30{ }^{\circ} \mathrm{C}$ for $1 \mathrm{~h}$ and was again centrifuged at $3000 \mathrm{rpm}$ for $5 \mathrm{~min}$. Following this, $5 \mathrm{~mL}$ of the supernatant, $1 \mathrm{~mL}$ of water, and $60 \mu \mathrm{L}$ of acetic acid were mixed together, and the mixture was applied to a MultiSep 229 Ochra. The eluate $(4 \mathrm{~mL})$ was dried at $40{ }^{\circ} \mathrm{C}$ under a nitrogen stream and dissolved in $400 \mu \mathrm{L}$ of a $10 \mathrm{mM}$ ammonium acetate aqueous solution/acetonitrile $(85: 15 v / v)$. Each sample was filtered with a $0.20 \mu \mathrm{m}$ PTFE filter immediately before LC-Orbitrap MS analysis.

\subsection{LC-Orbitrap MS Analysis}

The LC-Orbitrap MS analysis was performed using an Ultimate 3000 system coupled to a Q-Exactive ${ }^{\mathrm{TM}}$ mass spectrometer (Thermo Fisher Scientific, Bremen, Germany). The Xcalibur ${ }^{\mathrm{TM}} 2.2$ software (Thermo Fisher Scientific, Bremen, Germany) was used to control the instruments and to process the data.

LC was performed by using a $10 \mathrm{mM}$ ammonium acetate aqueous solution as solvent $\mathrm{A}$ and $2 \%$ acetic acid in methanol as solvent B [21]. The gradient profile used was 2\% B (0-2.0 min), 55\% B (3.0-4.0 min), 70\% B (4.1 $\mathrm{min}), 80 \% \mathrm{~B}$ (7.0 min), 95\% B (7.01-8.0 min), and 2\% B (8.01-11.0 min). The flow rate was set to $0.4 \mathrm{~mL} / \mathrm{min}$ and the column temperature was maintained at $40{ }^{\circ} \mathrm{C}$. The chromatographic separation was carried out on a Mastro C18 column $(2.1 \mathrm{~mm} \times 100 \mathrm{~mm}, 3 \mu \mathrm{m})$ obtained from Shimadzu GLC (Tokyo, Japan) using an injection volume of $5 \mu \mathrm{L}$.

The Q-Exactive ${ }^{\mathrm{TM}}$ mass spectrometer was operated in positive mode with a heated electrospray ionization source (HESI-II) and a spray voltage of $3.00 \mathrm{kV}$. The capillary and the heater temperatures were $350{ }^{\circ} \mathrm{C}$ and $300{ }^{\circ} \mathrm{C}$, respectively. The sheath gas and the auxiliary gas flow rates were applied 40 and 10 (in arbitrary units), respectively. The precursor ion scan was done in the full MS mode at a resolution of 70,000 at an $\mathrm{m} / \mathrm{z}$ value of 200 (3 scans/s), auto gain control (AGC) target of 3e6, maximum injection time (IT) of $100 \mathrm{~ms}$, and a scan range of $\mathrm{m} / z$ values of $100-1000$. The product ion scan was conducted in a data dependent $\mathrm{MS}^{2}$ mode $\left(\mathrm{dd}-\mathrm{MS}^{2}\right)$ using a resolution of 17,500 at a $\mathrm{m} / \mathrm{z}$ value of 200, AGC target of 2e5, maximum IT of $200 \mathrm{~ms}$, normalized collision energy (NCE) of $30 \mathrm{eV}$, stepped NCE of $50 \%$, and a scan range of $m / z 50-800$.

\subsection{Synthesis of FA1 from FBI and the Characterization of the Structures by NMR Analysis}

FA1 was synthesized from FB1 as follows [22,23]. FB1 weighed $4.61 \mathrm{mg}$ in a $50 \mathrm{~mL}$ recovery flask and was dissolved in $0.2 \mathrm{~mL}$ of $N, N$-dimethylformamide. Following this, $1.5 \mathrm{~mL}$ of $3 \mathrm{M}$ dipotassium hydrogen phosphate aqueous solution and $1.5 \mathrm{~mL}$ of acetic anhydride were added to the FB1 solution and stirred with a magnetic stirrer for $10 \mathrm{~min}$. To the reaction mixture, $3 \mathrm{~mL}$ of water was added, and the solution was further stirred for $30 \mathrm{~min}$. To this solution, $50 \mathrm{~mL}$ of water was added and the full volume of the reaction solution was loaded on the Supelpak 2 previously filled in an open column. 
The column loaded with the reaction solution was washed five times with $15 \mathrm{~mL}$ of water and once with $10 \mathrm{~mL}$ of $50 \%$ acetonitrile solution. The compounds were then extracted with $60 \mathrm{~mL}$ of $50 \%$ acetonitrile solution and the extract was evaporated to obtain $2.69 \mathrm{mg}$ of FA1. A portion of the FA1 was dissolved again with methanol- $\mathrm{d}_{4}$ and analyzed by NMR spectroscopy.

${ }^{1} \mathrm{H}$ NMR (600 MHz) and COSY spectra were recorded on a Bruker AV 600 instrument (Bruker, Karlsruhe, Germany), and the chemical shifts are expressed in terms of $\delta$ (ppm) relative to the solvent signal (methanol- $\mathrm{d}_{4}, \delta^{\mathrm{H}} 3.31, \delta^{\mathrm{C}} 49.0$ ).

\subsection{Validation of the Method}

The method was validated by evaluating the linearity, recovery, and the intraday precision using a corn grit sample which contained $9.3 \mu \mathrm{g} / \mathrm{kg}$ of FB1. (FB2, FB3, and FA1 were not detected.). The coefficient of linearity was determined from the calibration curves, which were constructed by plotting the peak areas of the prepared samples spiked with FA1, FB1, FB2, and FB3 standards against the concentrations of the analyte. The concentrations of FA1, FB1, FB2, and FB3 added to the samples were $5,10,50,100,500,1000$, and $5000 \mu \mathrm{g} / \mathrm{kg}$. To the sample, $50 \mu \mathrm{g} / \mathrm{kg}$ of FA1, FB1, FB2, and FB3 were added for recovery and intraday precision evaluations. The intraday precision was calculated by repeating the measurements five times on the same day and calculating the relative standard deviation of these measurements. The LODs and the LOQs were defined as the concentrations that gave a signal to noise ratio $(\mathrm{S} / \mathrm{N})$ of $3: 1$ and 10:1, respectively.

\section{Conclusions}

Three peaks of compounds I, II, and III (presumably representing FAs), as well as FBs were detected simultaneously from the corn sample naturally contaminated with fumonisins (MTC-9999E) using high-resolution LC-Orbitrap MS. In the case of FB1, FB2, and FB3, similar fragment ions generated by the cleavage of TCAs and the hydroxyl groups were observed at $m / z$ values of 200-800, and different ions (depending on the bonding position of the hydroxyl group in each compound) were detected at $m / z$ values of 50-200. From the results of the fragment ions analysis for the compounds, it was hypothesized that compounds I, II, and III have similar structures as FBs with the inclusion of an additional $\mathrm{C}_{2} \mathrm{H}_{2} \mathrm{O}$ bound to the compound. Further, compound $\mathrm{I}$ has the same retention time and product ion mass spectrum as those of FA1 synthesized from FB1 standard material. Based on these results, compound I was identified as FA1 and consequently, compounds II and III were hypothesized to be FA2 and FA3, respectively.

A method for determining of FA1, FB1, FB2, and FB3 was developed and the validated method was applied to the analysis of the MTC-9999E sample. The analytical levels calculated for FB1, FB2, and FB3 were within the acceptance limits, which reconfirmed the validity of the method. The amount of FA1 in MTC-9999E was determined to be $4.2 \mathrm{mg} / \mathrm{kg}$, which was approximately $15 \%$ of the amount of FB1.

These findings using high-resolution LC-Orbitrap MS indicate that corn may contain not only FBs but also FAs, as potential contaminants. Our method can be applied to control the occurrence of fumonisins in corn products. 


\section{Author Contributions}

Masayoshi Tamura, Naoki Mochizuki, and Yasushi Nagatomi conceived and designed the experiments. Masayoshi Tamura and Yasushi Nagatomi conducted the experiments and analyzed the data. Masayoshi Tamura wrote the manuscript. Naoki Mochizuki, Yasushi Nagatomi, Akira Toriba, and Kazuichi Hayakawa supervised the work and revised the manuscript for important intellectual content.

\section{Conflicts of Interest}

The authors declare no conflict of interest.

\section{References}

1. Hussein, H.S.; Brasel, J.M. Toxicity, metabolism, and impact of mycotoxins on humans and animals. Toxicology 2001, 167, 101-134.

2. Norred, W.P. Fumonisins-Mycotoxins prodused by Fusarium moniliforme. J. Toxicol. Environ. Health 1993, 38, 309-328.

3. International Agency for Research on Cancer (IARC). IARC Monographs on the Evaluation of Carcinogenic Risks to Humans; IARC Press: Lyon, France, 2002; Volume 82, pp. 301-366.

4. Food and Drug Administration (FDA). FDA regulatory guidance for mycotoxins. Available online: http:/www.ngfa.org/wp-content/uploads/NGFAComplianceGuideFDARegulatoryGuidanceforMycotoxins8-2011.pdf (accessed on 29 May 2014).

5. European Union. Commission Regulation (EC) No 1881/2006 setting maximum levels for certain contaminants in food-stuffs. Off. J. Eur. Union 2006, L364, 5-24.

6. Lazzaro, I.; Falavigna, C.; Dall'Asta, C.; Proctor, R.H.; Galaverna, G.; Battilani, P. Fumonisin B, $\mathrm{A}$ and $\mathrm{C}$ profile and masking in Fusarium verticillioides strains on fumonisin-inducing and maize-based media. Int. J. Food Microbiol. 2012, 159, 93-100.

7. Musser, S.M.; Eppley, R.M.; Mazzola, E.P.; Hadden, C.E.; Shockcor, J.P.; Crouch, R.C.; Martin, G.E. Identification of an $N$-acetyl keto derivative of fumonisin B1 in corn cultures of Fusarium proliferatum. J. Nat. Prod. 1995, 58, 1392-1397.

8. Musser, S.M.; Plattner, R.D. Fumonisin composition in cultures of Fusarium moniliforme, Fusarium proliferatum, and Fusarium nygami. J. Agric. Food Chem. 1997, 45, 1169-1173.

9. Rheeder, J.P.; Marasas, W.F.O.; Vismer, H.F. Production of fumonisin analogs by Fusarium species. Appl. Environ. Microbiol. 2002, 68, 2101-2105.

10. Sewram, V.; Mshicileli, N.; Shephard, G.S.; Vismer, H.F.; Rheeder, J.P.; Lee, Y.-W.; Leslie, J.F.; Marasas, W.F.O. Production of fumonisin B and C analogues by several Fusarium species. J. Agric. Food Chem. 2005, 53, 4861-4866.

11. Lazzaro, I.; Falavigna, C.; Galaverna, G.; Dall'Asta, C.; Battilani, P. Cornmeal and starch influence the dynamic of fumonisin $\mathrm{B}, \mathrm{A}$ and $\mathrm{C}$ production and masking in Fusarium verticillioides and F. proliferatum. Int. J. Food Microbiol. 2014, 166, 21-27. 
12. Van der Westhuizen, L.; Shephard, G.S.; Snyman, S.D.; Abel, S.; Swanevelder, S.; Gelderblom, W.C.A. Inhibition of sphingolipid biosynthesis in rat primary hepatocyte cultures by fumonisin $\mathrm{B}_{1}$ and other structurally related compounds. Food Chem. Toxicol. 1998, 36, 497-503.

13. Abbas, H.K.; Shier, W.T.; Seo, J.A.; Lee, Y.W.; Musser, S.M. Phytotoxicity and cytotoxicity of the fumonisin $\mathrm{C}$ and $\mathrm{P}$ series of mycotoxins from Fusarium spp. fungi. Toxicon 1998, 36, 2033-2037.

14. Songsermsakul, P.; Razzazi-Fazeli, E. A review of recent trends in applications of liquid chromatography-mass spectrometry for determination of mycotoxins. J. Liq. Chrom. Relat. Technol. 2008, 31, 1641-1686.

15. Rubert, J.; Soler, C.; Marín, R.; James, K.J.; Mañes, J. Mass spectgrometry strategies for mycotoxins analysis in Europian beers. Food Control 2013, 30, 122-128.

16. Herebian, D.; Zühlke, S.; Lamshöft, M.; Spiteller, M. Multi-Mycotoxin analysis in complex biological matrices using LC-ESI/MS: Experimental study using triple stage quadrupole and LTQ-Orbitrap. J. Sep. Sci. 2009, 32, 939-948.

17. Nakagawa, H.; Sakamoto, S.; Sago, Y.; Nagashima, H. Detection of type A trichothecene di-glucosides produced in corn by high-resolution liquid chromatography-orbitrap mass spectrometry. Toxins 2013, 5, 590-604.

18. Zachariasova, M.; Vaclavikova, M.; Lacina, O.; Vaclavik, L.; Hajslova, J. Deoxynivalenol oligoglycosides: "Masked" Fusarium toxins occurring in malt, beer, and breadstuff. J. Agric. Food Chem. 2012, 60, 9280-9291.

19. De Girolamo, A.; Lattanzio, V.M.; Schena, R.; Visconti, A.; Pascale, M. Use of liquid chromatography-high-resolution mass spectrometry for isolation and characterization of hydrolyzed fumonisins and relevant analysis in maize-based products. J. Mass Spectrom. 2014, 49, 297-305.

20. Månsson, M.; Klejnstrup, M.L.; Phipps, R.K.; Nielsen, K.F.; Frisvad, J.C.; Gotfredsen, C.H.; Larsen, T.O. Isolation and NMR characterization of fumonisin B2 and a new fumonisin B6 from Aspergillus niger. J. Agric. Food Chem. 2010, 58, 949-953.

21. Tamura, M.; Matsumoto, K.; Watanabe, J.; Iida, J.; Nagatomi, Y.; Mochizuki, N. Minimization of carryover for high-throughput liquid chromatography with tandem mass spectrometry analysis of 14 mycotoxins in corn grits. J. Sep. Sci. 2014, 37, 1552-1560.

22. Thomas Shier, W.; Abbas, H.K.; Badria, F.A. Complete structures of the sphingosine analog mycotoxin fumonisin $\mathrm{B} 1$ and ALL toxin $\mathrm{T}_{\mathrm{A}}$ : Absolute configuration of the side chains. Tetrahedron Lett. 1995, 36, 1571-1574.

23. Pan, S.C.; Dutcher, J.D. Separation of acetylated neomycins B and C by paper chromatography. Anal. Chem. 1956, 28, 836-838.

(C) 2014 by the authors; licensee MDPI, Basel, Switzerland. This article is an open access article distributed under the terms and conditions of the Creative Commons Attribution license (http://creativecommons.org/licenses/by/3.0/). 